\title{
Carbonaceous Aerosols in the Atmosphere
}

\author{
Daniele Contini ${ }^{1, *}$ (1D), Roberta Vecchi ${ }^{2}$ (i) and Mar Viana ${ }^{3}$ (i) \\ 1 Institute of Atmospheric Sciences and Climate, ISAC-CNR, National Research Council, Str. Prv. \\ Lecce-Monteroni km 1.2, 73100 Lecce, Italy \\ 2 Department of Physics, Università degli Studi di Milano and National Institute of Nuclear Physics-Milan, \\ via Celoria 16, 20133 Milan, Italy; roberta.vecchi@unimi.it \\ 3 Institute of Environmental Assessment and Water Research (IDAEA), Spanish Research Council (CSIC), \\ C/Jordi Girona, 18-26, 08034 Barcelona, Spain; mar.viana@idaea.csic.es \\ * Correspondence: d.contini@isac.cnr.it; Tel.: +39-0832-298919
}

Received: 7 May 2018; Accepted: 8 May 2018; Published: 10 May 2018

check for updates

\section{Introduction}

Scientific understanding of the processes involving carbonaceous aerosols in atmosphere is extremely important for both the climate and human health. This explains the increasing scientific interest in characterising these chemical species [1,2]. The carbonaceous fraction is an important component of atmospheric particulate matter, generally between $20 \%$ and $50 \%$ of the total aerosol mass [3,4]. Carbonaceous aerosols include an organic fraction, named organic carbon (OC), and a refractory light-absorbing component generally referred to as elemental carbon (EC, when quantified using thermal optical methods) or black carbon (BC, when quantified using optical methods). Sometimes, carbonate carbon can also contribute to total carbon concentrations in aerosol samples. Comparability of different thermal-optical protocols for OC and EC measurements ([5-8] and comparability of BC and EC measurements [9-12] are still issues in current research.

Black carbon (BC) in itself is also a current issue, both at local and global scales; it has a primary origin and it is emitted mainly from anthropogenic combustion sources, including industrial emissions, road transport, and domestic heating [13,14]. Characterised by strong light absorption, BC particles are largely responsible for positive radiative forcing by aerosols. However, there are large uncertainties in the spatial distributions and temporal trends of sources, its effective mixing state (internally mixed or core-shell), its size distribution, and in the ability of BC particles to nucleate ice [15-17]. These uncertainties limit the effectiveness of models in evaluating optical properties and predicting future scenarios, thus reducing our understanding of the role of $\mathrm{BC}$ in climate modelling. In addition, $\mathrm{BC}$ has adverse effects on human health, deteriorating air quality in countries all over the world. $\mathrm{BC}$ may not be a major directly toxic component of fine aerosol; however, it may act as a carrier of a wide variety of, especially, combustion-derived chemical constituents of varying toxicity to sensitive targets in the human body such as the lungs, the body's major defense cells and possibly systemic blood circulation [2].

As a result, $\mathrm{BC}$ could be an important target to simultaneously mitigate the health and climate effects of atmospheric aerosols.

Organic carbon (OC) is one of the largest contributors to particulate matter mass concentrations and it originates from different anthropogenic (combustion processes) and natural (sea-spray and biogenic emissions) sources. While BC has a primary origin, $\mathrm{OC}$ can be both primarily emitted but also formed in the atmosphere through condensation to the aerosol phase of low vapour pressure compounds emitted as primary pollutants or formed in the atmosphere $[18,19]$. Thereby, a large fraction of OC in the atmosphere has a secondary origin. Because of this, the OC/EC ratio in aerosol fractions differs widely, both in space and seasonally, and it could be a useful diagnostic ratio to 
investigate sources and processes happening in atmosphere, which can lead to the formation of secondary organic compounds [20-25]. Organic carbon is also characterised by a high solubility and it is one of the main drivers of the oxidative potential of atmospheric particles, with possible adverse health effects $[26,27]$.

Recently, the scientific community has addressed Brown Carbon $(\mathrm{BrC})$, a light-absorbing organic compound, whose characteristics are still largely unknown [28,29].

Understanding the properties and the dynamics of carbonaceous particles, contributions from main anthropogenic and natural sources, and carbonaceous aerosol transformations in atmosphere is still challenging and requires extensive research. This special issue (SI) addresses these open questions by compiling papers dealing with the different mentioned perspectives, including laboratory studies and measurement protocols, analysis of optical properties, source apportionment and carbonaceous particle emissions, as well as assessments of toxicity effects indicators and population exposure.

\section{Recent Advances in the Characterisation of Carbonaceous Aerosols}

This SI is a collection of recent advances in the characterisation of spatial and temporal trends of concentrations of carbonaceous aerosol, in advanced measurement methods and optical properties, in exposure and toxicity indicators, as well as discussion on the influence of the main anthropogenic sources. The following aspects are addressed in detail.

\subsection{Trends of Carbon Content in Atmospheric Aerosols}

Long-term trends of carbon concentrations in aerosols are important to investigate the trends of the impacts of combustion sources, as well as to have a baseline for modelling future scenarios of radiative forcing. Nevertheless, there is a lack of long-term studies of carbon content in aerosols because these measurements are generally not included in national air quality standards and, therefore, are not continuously monitored in several environmental monitoring networks. The main objective of the work of Di Ianni et al. [30] was to estimate the long-term trend (2001-2017) of "surface" equivalent black carbon mass concentration $(\mathrm{eBC})$ in Rome (Italy). This was obtained rescaling aerosol absorption columnar data (AERONET) to ground-level aerosol absorption. This absorption was converted into $\mathrm{eBC}$ mass concentration by using values of mixing layer height, derived from ceilometre measurements, and a mass-to-absorption conversion factor. A negative trend for eBC mass concentration of $-0.76 \mu \mathrm{g} / \mathrm{m}^{3} /$ decade was individuated. Instead, a positive trend was found for single scattering albedo (SSA), equal to $+0.014 /$ decade, indicating that the contribution of absorption to extinction is decreasing faster than that of scattering.

The concentration of OC and EC in atmospheric aerosols is influenced by several sources (natural and anthropogenic) and by the formation of secondary organic carbon affected by local meteorology. This produces important seasonal and diurnal variabilities in measured concentrations. Analysis of these variabilities could bring information regarding the impact of the main carbon sources to particulate matter. In Diapouli et al. [31], seasonal, weekly, and diurnal variability of equivalent black carbon (eBC) concentrations were investigated at a suburban site in Athens (Greece). A dataset was collected between 2013 and 2014 including absorption coefficients (at seven wavelengths), and $\mathrm{PM}_{2.5}$ chemical composition data for key biomass burning markers (levoglucosan, $\mathrm{K}, \mathrm{EC}$, and OC). The Aethalometer model was applied for the source apportionment of eBC quantifying the contribution of fossil fuel combustion $\left(\mathrm{BC}_{\mathrm{ff}}\right)$ and wood burning $\left(\mathrm{BC}_{\mathrm{wb}}\right)$. The main results indicated that $\mathrm{eBC}$ concentrations were equal to $2.4 \pm 1.0 \mu \mathrm{g} / \mathrm{m}^{3}$ (cold season) and $1.6 \pm 0.6 \mu \mathrm{g} / \mathrm{m}^{3}$ (warm season). The contribution from wood burning was significantly higher during the cold period $(21 \pm 11 \%$, versus $6 \pm 7 \%$ in the warm period). In Klejnowski et al. [32], the seasonal trend of carbon content in $\mathrm{PM}_{10}$ was investigated in the Krynica Zdroj area (Cracow, Poland) using data collected between 2016 and 2017. Results showed that OC, EC, and levoglucosan concentrations were at their maximum during the heating season for this site, with monthly mean total carbonaceous material/ $\mathrm{PM}_{10}$ ratios ranging between about 0.28 and 0.44 depending on the season. Analysis of the correlation between OC 
and levoglucosan (a tracer of biomass burning) showed that biomass burning was an important source of aerosol particles affecting local air quality.

The variability of anthropogenic sources and the influence of meteorological parameters (temperature, humidity, and solar radiation) on the formation of secondary organic aerosols induces diurnal variability in the carbon content of atmospheric aerosols. The study of this variability could shed light on the relative importance of these processes compared to diurnal cycles of sources. In the work of Ye et al. [33], the day-night differences of a suite of chemical species including elemental carbon (EC), organic carbon (OC), water-soluble organic carbon (WSOC), water-soluble organic nitrogen (WSON), selected polycyclic aromatic hydrocarbons (PAHs), and secondary inorganic ions $\left(\mathrm{NO}_{3}{ }^{-}, \mathrm{SO}_{4}{ }^{2-}, \mathrm{NH}_{4}{ }^{+}\right)$in $\mathrm{PM}_{2.5}$ was investigated in summer in Changzhou (China). The carbon content of humic-like substances (HULIS-C) was a significant portion of WSOC $(\sim 60 \%)$ and the latter accounted for, on average, about $60 \%$ of OC. A strong correlation was found between WSOC, HULIS-C and $\mathrm{O}_{3}$, implying that HULIS-C, similar to WSOC, was mainly composed of secondary species. PAHs, EC, and WSON showed higher mass concentration in the night and the WSOC/OC ratio was high in both day and night, indicating that secondary organic aerosol formation could occur throughout the day. The higher ratio during daytime suggested an important contribution from daytime photochemical oxidation.

\subsection{Exposure and Toxicity}

This section compiles results from studies addressing the exposure and subsequent toxicity of carbonaceous aerosols. While exposure to road traffic emissions (a major contributor to urban carbonaceous species) seems almost unavoidable in our cities today, it may be reduced as a function of means of transportation or commuting routes. This issue is analysed by Jereb et al. [34], who quantify $\mathrm{BC}$ concentrations at chosen sites and cycling routes in Slovenia and conclude that exposure can indeed be reduced through adequate urban and traffic planning and management. Dekoninck \& Int Panis [35], on the other hand, focus on the influence of transportation modes and assess the exposure of car drivers to BC with a microscopic land-use regression approach, taking into account regulatory interventions (e.g., the Euro 5 Particulate Matter Standard). This kind of exposure estimate is especially relevant for epidemiologists and policy makers. The underlying motivation for exposure assessment studies is the toxicity of aerosol particles, and its potential dependence on particle chemical composition. The work by Samara [36] compares the redox activity of water-soluble urban aerosols from two urban sites in Thessaloniki and concludes that the quasi-ultrafine particle mode $(<0.49 \mu \mathrm{m})$ exhibited the lowest activity in comparison to larger particles. Vehicle tailpipe emissions and biomass burning are seen to influence the oxidative potential of PM. Finally, the question of aerosol toxicity was also addressed (among other questions) by the CARE experiment [37]. In an integrative approach, this study addresses air quality, health and climate implications of aerosol pollution. It provides baseline levels of carbonaceous aerosols for Rome and concludes on the need for an update of existing air quality standards for $\mathrm{PM}_{10}$ and $\mathrm{PM}_{2.5}$ with regard to particle composition and size distribution, and the data averaging period.

\subsection{Advanced Measurement Methods and Optical Properties}

Due to the complexity of the aerosol carbonaceous components, there are currently large uncertainties in the assessment of their physical-chemical-optical properties and source apportionment; in addition, issues about their role in affecting the Earth's radiation budget, visibility and health effects are still under investigation. With the aim of filling this gap, research on this topic has grown a lot in recent years and advanced experimental and modelling approaches have been proposed.

As far as the radiative budget of the atmosphere is concerned, in the last decade, brown carbon $(\mathrm{BrC})$ has assumed an increasing importance because this organic material shows enhanced absorption at short wavelengths thus possibly playing a non-negligible role in the energy balance of the atmosphere. $\mathrm{BrC}$ is indeed the major focus of some of the papers published in this SI, due to the 
lack of detailed information about its properties and sources. Indeed, $\mathrm{BrC}$ is still poorly characterised, although it is widely recognised that HULIS (humic-like substances) are among its major components; the latter are macromolecules belonging to the organic aerosol component, primarily emitted by biomass burning or formed in atmosphere, e.g., by photochemical processes. Lee et al. [38] investigated the sensitivity of the optical properties of HULIS based on field data and simulations based on Mie theory. They focused mainly on hygroscopicity, a parameter of relevance in radiative forcing due to both indirect (e.g., aerosols acting as cloud condensation nuclei) and direct effects (e.g., altering aerosol chemical composition and optical properties), although scarcely studied. Other parameters such as the aerosol size distribution and the imaginary refractive index (IRI) of HULIS (the latter characterising the absorption properties of this carbonaceous component) were addressed as contributing to uncertainties in radiative forcing (RF) estimates. Results of the study by Lee et al. [38] showed that at the GAW background site of Anmyeon Island in Korea, HULIS comprised 32-80\% of the carbonaceous component absorption coefficient and that the hygroscopic properties of HULIS strongly affected their optical behaviour. Indeed, radiative forcing estimates indicate that HULIS were significant contributors and RF was negatively enhanced (i.e., from -0.11 to $-0.192 \mathrm{~W} / \mathrm{m}^{2}$ ) as the hygroscopic growth factor increased from 1.0 to 1.3 .

The formation of moderately brown secondary organic aerosols in biogenically-influenced urban air was observed during the CARES campaign by Gyawali et al. [39]. This study highlights the role of the interaction between anthropogenic and biogenic atmospheric components in enhancing the production of secondary organic aerosols (SOA) during intense photochemical events and air masses advection. Gyawali et al. [39] investigated mass absorption coefficients (MAC), associated uncertainties, and frequency distributions. These are relevant parameters in climate models and in Gyawali et al. [39] were obtained by regression analysis on photoacoustic (PA) and single particle soot photometer (SP2) data and simulated by the Monte Carlo method. In particular, SOA optical properties were addressed and a modest increase in light absorption in the UV range was observed for SOA compared to biomass burning aerosols as derived from multi-spectral measurements. To brown SOA (and perhaps to a mineral dust contribution) was most likely ascribed the observed enhancement of light absorption rather than to the additional coating of non-absorbing SOA on aged BC particles.

Multi-wavelength measurements are also very effective in source apportionment studies based on light absorption measurements. This is the approach presented by Bernardoni et al. [40], who applied the recently proposed MWAA model (Multi Wavelength Absorption Analyzer) to provide a source (fossil fuel combustion vs. biomass burning) as well as a component ( $\mathrm{BC}$ vs. $\mathrm{BrC}$ ) apportionment of the aerosol absorption coefficient. In addition, the BrC Ångström absorption exponent $\left(\alpha_{\mathrm{BrC}}\right)$ is a noteworthy output of the model. The model-stemming from the well-known Aethalometer model introduced by Sandradewi et al. [41] —aims at providing information about BrC, whose chemical complexity and ageing in the atmosphere affects optical properties and whose sources are of interest. The authors underlined that data on $\mathrm{BrC}$ optical properties typically reported in the literature are largely related to water or solvent extracts and, thus, are poorly representative of airborne aerosols. This issue was tackled in the study by analysing the absorption coefficient using filter-based measurements through multi-lambda home-made instrumentation. The proposed experimental and modelling methodology was applied at a rural and an urban site in Northern Italy where EC and OC were apportioned to wood burning and fossil fuel combustion sources. It is worth noting that the result for $\alpha_{\mathrm{BrC}}$ was $3.8 \pm 0.1$, which was fully comparable at the two monitoring sites. In addition, the authors speculated about the non-suitability of the two-source approach, especially at heavily polluted sites impacted by many different sources and where atmospheric processing can be effective in changing aerosol properties.

Carbonaceous aerosol source apportionment (i.e., fossil vs. non-fossil) can be robustly performed through radiocarbon analysis on total carbon (TC), a reliable method based on the absence of ${ }^{14} \mathrm{C}$ in fossil fuels. Nevertheless, the disentanglement between biomass and biogenic emissions (i.e., contemporary sources) is a further improvement in source apportionment requiring ${ }^{14} \mathrm{C}$ 
analysis on EC and OC separately and given a known OC/EC emission ratio for biomass burning. Zenker et al. [42] reported on the most important tricky points in radiocarbon analysis on OC and EC and presented the results of an inter-comparison study carried out among three laboratories in Europe. A focus of the paper was on experimental issues related to the EC-OC separation by thermal methods, which is well-known to be dependent on the temperature protocol. The authors also confirmed what was reported already in previous literature about EC underestimation when using the EUSAAR-2 protocol on untreated samples, thus suggesting that EC measurements on water-extracted samples are more reliable, especially when heavy loaded filters are analysed. Together with this problem, Zenker et al. [42] claimed there is a lack in available EC reference materials for ${ }^{14} \mathrm{C}$ analysis in aerosols and noted the need for more comprehensive inter-comparison studies.

\subsection{Characteristics of Carbonaceous Aerosol at Different Sites}

Although in recent years the carbonaceous aerosol component has been extensively studied regarding its abundance, characteristics, and sources, there are areas particularly interesting from the pollution point of view where such data are still lacking. This is the case of the Mediterranean basin-one of the most fragile climatic zones on the planet, which is impacted by anthropogenic emissions, biomass burning, and natural sources (e.g., marine emissions and Saharan dust events) - where the paucity of OC and EC data is especially observed in the southern part of the Italian peninsula. The study by Dinoi et al. [43] reports results of a field campaign on EC and OC measurements carried out during wintertime 2016 at five different sites in Southern Italy. Urban, suburban, coastal/marine and remote locations were selected to map the spatial distribution of EC and OC on both $\mathrm{PM}_{10}$ and $\mathrm{PM}_{2.5}$ applying the same experimental approach in order to avoid biases due to differences in the thermal protocols used to quantify the two carbonaceous fractions. The average concentrations of both OC and EC were markedly differed from site to site, with the highest ones recorded at the urban and suburban sites.

Similarly, studies devoted to the assessment of the spatial and temporal distribution of carbonaceous aerosols are going on in China, where emissions have increased mainly due to anthropogenic sources. In the paper by Huang et al. [44], a year-long dataset with hourly resolution showed typical diurnal patterns of EC and OC $\mathrm{PM}_{2.5}$ observed during different seasons at Wanzhou, an urban area in Southwestern China. The high temporal resolution helped in identifying the role of local source emissions vs. meteorological conditions and advection phenomena. Wang et al. [45] investigated carbonaceous aerosol size-segregated distribution in an industrial city in China in the Yangtze River Delta during different seasons. Size-segregated datasets are extremely useful to better identify source emissions, to evaluate light extinction and to assess their impact on climate and health effects; nevertheless, size-segregated studies on aerosol chemical composition are quite scarce due to the heavy work load required in the field, as well as in the lab.

One open issue in PM extensive monitoring studies is related to the quantification of SOA (secondary organic aerosol) as it generally requires sophisticated analytical techniques (e.g., aerosol mass spectrometry) not widespread yet. In all the above-mentioned papers, a simple approach based on the "OC/EC minimum ratio" was applied to tentatively apportion the secondary organic aerosol to total OC, highlighting the limitations and high uncertainties associated with this method. Results showed that SOA represented a considerable fraction of OC in the Mediterranean area (up to ca. 60\%) and in the industrial city of Nanjing while OC was dominated by primary organic carbon (with the only exception being autumn samples) in the urban area of Wanzhou.

A challenging task is typically the attribution of SOA back to its precursors. This would be a very useful piece of information to design effective strategies aimed at PM reduction. Maenhaut et al. [46] conducted a summertime field campaign at the forested background site of K-puszta in Hungary, where fine aerosol is dominated by SOA mainly produced by biogenic volatile organic compounds (VOCs). In this paper, the authors claimed that by assessing the biogenic fraction of PM-which is, in principle, impossible to abate-it is possible to estimate the fraction of PM that could be reduced by 
appropriate measures, thus pointing at the importance of measurements of biogenic contributions to PM. Despite the several techniques used by the authors to analyse the samples, results showed that a large fraction (more than $90 \%$ ) of OC in $\mathrm{PM}_{2.5}$ remained undetermined, thus supporting the need for improved analytical methods aimed at the molecular characterisation of OC.

\section{Concluding Remarks}

The results presented are highlights of some of the recent advances in the characterisation of carbonaceous aerosols in the atmosphere. They evidence the complexity of the chemical-physical processes involving carbon in the atmosphere, covering different aspects such as spatial and temporal trends, as well as exposure and toxicity of carbonaceous particles. Results also show that recent advances in measurement techniques and source apportionment may be powerful and sophisticated tools to provide high quality scientific information.

Author Contributions: D.C. initiated, conceptualised and designed the framework; D.C., R.V., and M.V. initiated the special issue and invited contributions; D.C., R.V., and M.V. edited the special issue, drafted the editorial paper and contributed to revisions and comments.

Conflicts of Interest: The authors declare no conflict of interest.

\section{References}

1. Bond, T.C.; Doherty, S.J.; Fahey, D.W.; Forster, P.M.; Berntsen, T.; DeAngelo, B.J.; Flanner, M.G.; Ghan, S.; Kaercher, B.; Koch, D.; et al. Bounding the role of black carbon in the climate system: A scientific assessment. J. Geophys. Res. Atmos. 2013, 118, 5380-5552. [CrossRef]

2. Janssen, N.A.H.; Hoek, G.; Simic-Lawson, M.; Fischer, P.; van Bree, L.; ten Brink, H.; Keuken, M.; Atkinson, R.W.; Anderson, H.R.; Brunekreef, B.; et al. Black carbon as an additional indicator of the adverse health effects of airborne particles compared with $\mathrm{PM}_{10}$ and $\mathrm{PM}_{2.5}$. Environ. Health Perspect. 2011, 119, 1691-1699. [CrossRef] [PubMed]

3. Kanakidou, M.; Seinfeld, J.H.; Pandis, S.N.; Barnes, I.; Dentener, F.J.; Facchini, M.C.; Van Dingenen, R.; Ervens, B.; Nenes, A.; Nielsen, C.J.; et al. Organic aerosol and global climate modelling: A review. Atmos. Chem. Phys. 2005, 5, 1053-1123. [CrossRef]

4. Putaud, J.P.; Van Dingenen, R.; Alastuey, A.; Bauer, H.; Birmili, W.; Cyrys, J.; Flentje, H.; Fuzzi, S.; Gehrig, R.; Hansson, H.C.; et al. A European aerosol phenomenology-3: Physical and chemical characteristics of particulate matter from 60 rural, urban, and kerbside sites across Europe. Atmos. Environ. 2010, 44, 1308-1320. [CrossRef]

5. Cavalli, F.; Viana, M.; Yttri, K.E.; Genberg, J.; Putaud, J.P. Toward a standardised thermal-optical protocol for measuring atmospheric organic and elemental carbon: The EUSAAR protocol. Atmos. Meas. Tech. 2010, 3 , 79-89. [CrossRef]

6. Piazzalunga, A.; Bernardoni, V.; Fermo, P.; Valli, G.; Vecchi, R. Technical note: On the effect of water-soluble compounds removal on EC quantification by TOT analysis in aerosol samples. Atmos. Chem. Phys. 2011, 11, 10193-10203. [CrossRef]

7. Cheng, Y.; Duan, F.; He, K.; Du, Z.; Zheng, M.; Ma, Y. Intercomparison of thermal-optical method with different temperature protocols: Implications from source samples and solvent extraction. Atmos. Environ. 2012, 61, 453-462. [CrossRef]

8. Giannoni, M.; Calzolai, G.; Chiari, M.; Cincinelli, A.; Lucarelli, F.; Martellini, T.; Nava, S. A comparison between thermal-optical transmittance elemental carbon measured by different protocols in $\mathrm{PM}_{2.5}$ samples. Sci. Total Environ. 2016, 571, 195-205. [CrossRef] [PubMed]

9. Reisinger, P.; Wonaschütz, A.; Hitzenberger, R.; Petzold, A.; Bauer, H.; Jankowski, N.; Puxbaum, H.; Chi, X.; Maenhaut, W. Intercomparison of measurement techniques for black or elemental carbon under urban background conditions in wintertime: Influence of biomass combustion. Environ. Sci. Technol. 2008, 42, 884-889. [CrossRef] [PubMed]

10. Kanaya, Y.; Komazaki, Y.; Pochanart, P.; Liu, Y.; Akimoto, H.; Gao, J.; Wang, T.; Wang, Z. Mass concentrations of black carbon measured by four instruments in the middle of Central east China in June 2006. Atmos. Chem. Phys. 2008, 8, 7637-7649. [CrossRef] 
11. Ram, K.; Sarin, M.M.; Tripathi, S.N. Inter-comparison of thermal and optical methods for determination of atmospheric black carbon and attenuation coefficient from an urban location in northern India. Atmos. Res. 2010, 97, 335-342. [CrossRef]

12. Salako, G.O.; Hopke, P.K.; Cohen, D.D.; Begum, B.A.; Biswas, S.K.; Pandit, G.G.; Chung, Y.; Rahman, S.A.; Hamzah, M.S.; Davy, P.; et al. Exploring the Variation between EC and BC in a Variety of Locations. Aerosol Air Qual. Res. 2012, 12, 1-7. [CrossRef]

13. Querol, X.; Alastuey, A.; Viana, M.; Moreno, T.; Reche, C.; Minguillón, M.C.; Ripoll, A.; Pandolfi, M.; Amato, F.; Karanasiou, A.; et al. Variability of carbonaceous aerosols in remote, rural, urban and industrial environments in Spain: Implications for air quality policy. Atmos. Chem. Phys. 2013, 13, 6185-6206. [CrossRef]

14. Sandrini, S.; Fuzzi, S.; Piazzalunga, A.; Prati, P.; Bonasoni, P.; Cavalli, F.; Bove, M.C.; Calvello, M.; Cappelletti, D.; Colombi, C.; et al. Spatial and seasonal variability of carbonaceous aerosol across Italy. Atmos. Environ. 2014, 99, 587-598. [CrossRef]

15. Intergovernmental Panel on Climate Change (IPCC). Fifth Assessment Report: Climate Change 2013: The Physical Science Basis, Contribution of Working Group I to the Fifth Assessment Report of the Intergovernmental Panel on Climate Change; Stocker, T.F., Qin, D., Plattner, G.-K., Tignor, M., Allen, S.K., Doschung, J., Nauels, A., Xia, Y., Bex, V., Midgley, P.M., Eds.; Cambridge University Press: Cambridge, UK, 2013; 1535p.

16. Fuzzi, S.; Baltensperger, U.; Carslaw, K.; Decesari, S.; Van Der Gon, H.D.; Facchini, M.C.; Fowler, D.; Koren, I.; Langford, B.; Lohmann, U.; et al. Particulate matter, air quality and climate: Lessons learned and future needs. Atmos. Chem. Phys. 2015, 15, 8217-8299. [CrossRef]

17. Ullrich, R.; Hoose, C.; Möhler, O.; Niemand, M.; Wagner, R.; Höhler, K.; Hiranuma, N.; Saathoff, H.; Leisner, T. A New Ice Nucleation Active Site Parameterization for Desert Dust and Soot. J. Atmos. Sci. 2017, 74, 699-717. [CrossRef]

18. Gentner, D.R.; Isaacman, G.; Worton, D.R.; Chan, A.W.H.; Dallmann, T.R.; Davis, L.; Liu, S.; Day, D.A.; Russell, L.M.; Wilson, K.R.; et al. Elucidating secondary organic aerosol from diesel and gasoline vehicles through detailed characterization of organic carbon emissions. Proc. Natl. Acad. Sci. USA 2012, 109, 18318-18323. [CrossRef] [PubMed]

19. Robinson, A.L.; Donahue, N.M.; Shrivastava, M.K.; Weitkamp, E.A.; Sage, A.M.; Grieshop, A.P.; Lane, T.E.; Pierce, J.R.; Pandis, S.N. Rethinking organic aerosols: Semivolatile emissions and photochemical aging. Science 2007, 315, 1259-1262. [CrossRef] [PubMed]

20. Lonati, G.; Ozgen, S.; Giugliano, M. Primary and secondary carbonaceous species in $\mathrm{PM}_{2.5}$ samples in Milan (Italy). Atmos. Environ. 2007, 41, 4599-4610. [CrossRef]

21. Na, K.; Sawant, A.A.; Song, C.; Cocker, D.R. Primary and secondary carbonaceous species in the atmosphere ofWestern Riverside County, California. Atmos. Environ. 2004, 38, 1345-1355. [CrossRef]

22. Yang, F.; Huang, L.; Duan, F.; Zhang, W.; He, K.; Ma, Y.; Brook, J.R.; Tan, J.; Zhao, Q.; Cheng, Y. Carbonaceous species in $\mathrm{PM}_{2.5}$ at a pair of rural/urban sites in Beijing, 2005-2008. Atmos. Chem. Phys. 2011, 11, 7893-7903. [CrossRef]

23. Pio, C.; Cerqueira, M.; Harrison, R.M.; Nunes, T.; Mirante, F.; Alves, C.; Oliveira, C.; Sanchez de la Campa, A.; Artinano, B.; Matos, M. OC/EC ratio observations in Europe: Re-thinking the approach for apportionment between primary and secondary organic carbon. Atmos. Environ. 2011, 45, 6121-6132. [CrossRef]

24. Cheng, Y.; He, K.; Duan, F.; Du, Z.; Zheng, M.; Ma, Y. Ambient organic carbon to elemental carbon ratios: Influence of the thermal-optical temperature protocol and implications. Sci. Total Environ. 2014, 468-469, 1103-1111. [CrossRef] [PubMed]

25. Cesari, D.; Merico, E.; Dinoi, A.; Marinoni, A.; Bonasoni, P.; Contini, D. Seasonal variability of carbonaceous aerosols in an urban background area in Southern Italy. Atmos. Res. 2018, 200, 97-108. [CrossRef]

26. Chirizzi, D.; Cesari, D.; Guascito, M.R.; Dinoi, A.; Giotta, L.; Donateo, A.; Contini, D. Influence of Saharan dust outbreaks and carbon content on oxidative potential of water-soluble fractions of $\mathrm{PM}_{2.5}$ and $\mathrm{PM}_{10}$. Atmos. Environ. 2017, 163, 1-8. [CrossRef]

27. Velali, E.; Papachristou, E.; Pantazaki, A.; Choli-Papadopoulou, T.; Planou, S.; Kouras, A.; Manoli, E.; Besis, A.; Voutsa, D.; Samara, C. Redox activity and in vitro bioactivity of the water-soluble fraction of urban particulate matter in relation to particle size and chemical composition. Environ. Pollut. 2016, 208, 774-786. [CrossRef] [PubMed]

28. Laskin, A.; Laskin, J.; Nizkorodov, S.A. Chemistry of atmospheric brown carbon. Chem. Rev. 2015, 115, 4335-4382. [CrossRef] [PubMed] 
29. Wu, G.M.; Cong, Z.Y.; Kang, S.C.; Kawamura, K.; Fu, P.Q.; Zhang, Y.L.; Wan, X.; Gao, S.P.; Liu, B. Brown carbon in the cryosphere: Current knowledge and perspective. Adv. Clim. Chang. Res. 2016, 7, 82-89. [CrossRef]

30. Di Ianni, A.; Costabile, F.; Barnaba, F.; Di Liberto, L.; Weinhold, K.; Wiedensohler, A.; Struckmeier, C.; Drewnick, F.; Gobbi, G.P. Black Carbon Aerosol in Rome (Italy): Inference of a Long-Term (2001-2017) Record and Related Trends from AERONET Sun-Photometry Data. Atmosphere 2018, 9, 81. [CrossRef]

31. Diapouli, E.; Kalogridis, A.C.; Markantonaki, C.; Vratolis, S.; Fetfatzis, P.; Colombi, C.; Eleftheriadis, K. Annual Variability of Black Carbon Concentrations Originating from Biomass and Fossil Fuel Combustion for the Suburban Aerosol in Athens, Greece. Atmosphere 2017, 8, 234. [CrossRef]

32. Klejnowski, K.; Janoszka, K.; Czaplicka, M. Characterization and Seasonal Variations of Organic and Elemental Carbon and Levoglucosan in $\mathrm{PM}_{10}$ in Krynica Zdroj, Poland. Atmosphere 2017, 8, 190. [CrossRef]

33. Ye, Z.; Li, Q.; Ma, S.; Zhou, Q.; Gu, Y.; Su, Y.; Chen, Y.; Chen, H.; Wang, J.; Ge, X. Summertime Day-Night Differences of $\mathrm{PM}_{2.5}$ Components (Inorganic Ions, OC, EC, WSOC, WSON, HULIS, and PAHs) in Changzhou, China. Atmosphere 2017, 8, 189. [CrossRef]

34. Jereb, B.; Batkovič, T.; Herman, L.; Šipek, G.; Kovše, Š.; Gregorič, A.; Močnik, G. Exposure to Black Carbon during Bicycle Commuting-Alternative Route Selection. Atmosphere 2018, 9, 21. [CrossRef]

35. Dekoninck, L.; Int Panis, L. A High Resolution Spatiotemporal Model for In-Vehicle Black Carbon Exposure: Quantifying the In-Vehicle Exposure Reduction Due to the Euro 5 Particulate Matter Standard Legislation. Atmosphere 2017, 8, 230. [CrossRef]

36. Samara, C. On the Redox Activity of Urban Aerosol Particles: Implications for Size Distribution and Relationships with Organic Aerosol Components. Atmosphere 2017, 8, 205. [CrossRef]

37. Costabile, F.; Alas, H.; Aufderheide, M.; Avino, P.; Amato, F.; Argentini, S.; Barnaba, F.; Berico, M.; Bernardoni, V.; Biondi, R.; et al. First Results of the "Carbonaceous Aerosol in Rome and Environs (CARE)" Experiment: Beyond Current Standards for $\mathrm{PM}_{10}$. Atmosphere 2017, 8, 249. [CrossRef]

38. Lee, J.Y.; Jung, C.H.; Kim, Y.P. Estimation of Optical Properties for HULIS Aerosols at Anmyeon Island, Korea. Atmosphere 2017, 8, 120. [CrossRef]

39. Gyawali, M.; Arnott, W.P.; Zaveri, R.A.; Song, C.; Flowers, B.; Dubey, M.K.; Setyan, A.; Zhang, Q.; China, S.; Mazzoleni, C.; et al. Evolution of Multispectral Aerosol Absorption Properties in a Biogenically-Influenced Urban Environment during the CARES Campaign. Atmosphere 2017, 8, 217. [CrossRef]

40. Bernardoni, V.; Pileci, R.E.; Caponi, L.; Massabò, D. The Multi-Wavelength Absorption Analyzer (MWAA) Model as a Tool for Source and Component Apportionment Based on Aerosol Absorption Properties: Application to Samples Collected in Different Environments. Atmosphere 2017, 8, 218. [CrossRef]

41. Sandradewi, J.; Prévôt, A.S.; Szidat, S.; Perron, N.; Alfarra, M.R.; Lanz, V.A.; Weingartner, E.; Baltensperger, U. Using aerosol light absorption measurements for the quantitative determination of wood burning and traffic emission contributions to particulate matter. Environ. Sci. Technol. 2008, 42, 3316-3323. [CrossRef] [PubMed]

42. Zenker, K.; Vonwiller, M.; Szidat, S.; Calzolai, G.; Giannoni, M.; Bernardoni, V.; Jedynska, A.D.; Henzing, B.; Meijer, H.A.J.; Dusek, U. Evaluation and Inter-Comparison of Oxygen-Based OC-EC Separation Methods for Radiocarbon Analysis of Ambient Aerosol Particle Samples. Atmosphere 2017, 8, 226. [CrossRef]

43. Dinoi, A.; Cesari, D.; Marinoni, A.; Bonasoni, P.; Riccio, A.; Chianese, E.; Tirimberio, G.; Naccarato, A.; Sprovieri, F.; Andreoli, V.; et al. Inter-Comparison of Carbon Content in $\mathrm{PM}_{2.5}$ and $\mathrm{PM}_{10}$ Collected at Five Measurement Sites in Southern Italy. Atmosphere 2017, 8, 243. [CrossRef]

44. Huang, Y.; Liu, Y.; Zhang, L.; Peng, C.; Yang, F. Characteristics of Carbonaceous Aerosol in PM 2.5 at Wanzhou in the Southwest of China. Atmosphere 2018, 9, 37. [CrossRef]

45. Wang, H.; An, J.; Zhu, B.; Shen, L.; Duan, Q.; Shi, Y. Characteristics of Carbonaceous Aerosol in a Typical Industrial City—Nanjing in Yangtze River Delta, China: Size Distributions, Seasonal Variations, and Sources. Atmosphere 2017, 8, 73. [CrossRef]

46. Maenhaut, W.; Chi, X.; Wang, W.; Cafmeyer, J.; Yasmeen, F.; Vermeylen, R.; Szmigielska, K.; Janssens, I.A.; Claeys, M. Contribution from Selected Organic Species to $\mathrm{PM}_{2.5}$ Aerosol during a Summer Field Campaign at K-Puszta, Hungary. Atmosphere 2017, 8, 221. [CrossRef]

(C) 2018 by the authors. Licensee MDPI, Basel, Switzerland. This article is an open access article distributed under the terms and conditions of the Creative Commons Attribution (CC BY) license (http:/ / creativecommons.org/licenses/by/4.0/). 